AUDIT

\title{
Guidelines, compliance, and effectiveness: a 12 months' audit in an acute district general healthcare trust on the two week rule for suspected colorectal cancer
}

\author{
D Debnath, N Dielehner, K A Gunning
}

Postgrad Med J 2002;78:748-751

\begin{abstract}
Objectives: The Department of Health had recently introduced guidelines so that all suspected colorectal cancer patients could be seen by a specialist within two weeks of referral by their general practitioners. The usefulness and practicality of such a decision had been questioned. The aims of this study were to measure the compliance to the guidelines and evaluate the effectiveness of such referrals.

Methods: All patients who were referred to the rapid access colorectal clinic between August 2000 and July 2001 were included.

Settings: Darlington Memorial Hospital and Bishop Auckland General Hospital, both under South Durham Health Care Trust, were considered for the study.

Measures: Date of referral, referring practitioner, time of appointment, reasons for referral, and diagnosis.

Results: A total of 239 referrals were made; $96.2 \%$ of patients were given appointments within two weeks. Rectal bleed was the commonest $(32 \%)$ cause for referral. Diverticular disease was the most frequent $(29 \%)$ condition diagnosed. Altogether $97.4 \%$ of referrals were incomplete and $37.6 \%$ did not comply with the guidelines. Twenty one colorectal cancers $(8.9 \%)$ were diagnosed. The early cancer detection rate was $4.6 \%$.

Conclusions: This audit showed that compliance to the guidelines was associated with a higher cancer detection rate. The majority of patients received appointments within two weeks. Contrary to some speculations, the number of referrals was not limitless. However a high number of referrals failed to adhere to the guidelines. The cancer (particularly early cancer) detection rate was disappointingly low. This does not reflect an efficient system of referral and potential benefits to patients remain questionable.
\end{abstract}

See end of article for authors' affiliations

Correspondence to: Mr D Debnath, Department of Surgery, Polwarth Buildings, Foresterhill Aberdeen AB25 2ZD, UK d.debnath@abdn.ac.uk

Submitted 24 April 2002 Accepted

8 October 2002

C olorectal cancer is the second commonest malignancy in England and Wales. ${ }^{1}$ Altogether 30000 new cases are diagnosed per annum, with approximately $40 \%$ of patients surviving for five years. Survival from bowel cancer in Britain is worse than in the United States and Europe. This may be due to late presentation, as the disease is incurable on diagnosis in almost a quarter of patients in the UK. ${ }^{2}$

In July 2000 the Department of Health of England and Wales introduced a "two week rule". It would guarantee that anyone with suspected colorectal cancer would see a specialist within two weeks of their general practitioners' (GPs) request for an urgent appointment.

Experience with breast cancer over last three years suggested that any such rapid access clinic could potentially be flooded with patients with benign conditions. Ninety per cent of women attending the "rapid access breast cancer clinic" do not have breast cancer. ${ }^{3}$ Therefore, it is feared that a lack of careful selection of patients before referral may lead to over-investigations and unnecessary worries. It may also increase waiting times of routine clinics and cause occasional harm to patients who do not suffer from cancer.

Hence specific guidelines have been outlined to select the most appropriate patients (box 1). These guidelines ${ }^{14}$ are evidence based and derived from a series of audited databases. GPs were informed of these guidelines at meetings as well as by mail.

\section{METHODS}

South Durham Health Care Trust serves a population of almost 225000 in the north east of England. All patients referred to the trust between 1 August 2000 and 31 July 2001 were included in the study. Referrals were made by GPs on designated forms. The latter was custom-made and included titled boxes in order to accommodate the relevant information as outlined in box 1 . The central appointments team of the trust dealt with all the referrals and surgeons had no involvement in that matter. Appointments were allocated to either Darlington Memorial Hospital or Bishop Auckland General Hospital, depending on where patients lived.

The following data were obtained from case notes, supplemented by computer based data on radiology and pathology:

1. Date of referral.

2. Referring practice and the GP.

3. Time of appointment. The two week period was calculated from the day the appointment letter was written (rather than when it was received) and inclusive of weekends and bank holidays.

4. Reasons for referral. It was assessed whether the referrals were complete and whether the guidelines were adhered to.

5. Diagnosis (including site and stage, if the diagnosis was cancer).

A literature search was performed by using Medline and relevant web sites were also consulted. Statistical analysis was performed by using SPSS 10.1 statistical package.

\section{RESULTS}

A total of 239 patients were referred to the rapid access colorectal clinic during the one year period. Ninety two GPs and 26 


\section{Box 1: Guidelines for referral to the rapid access colorectal clinic}

\section{Referral guidelines for the general practitioner}

Patients with suspected cancer must be seen by a specialist within two weeks. If cancer is suspected, to ensure that it is dealt with urgently, please mark your fax:

Urgent referral: suspected cancer (two week rule applies)

This rule applies to suspected cancers, but does not apply to other types of urgent referrals.

\section{Contents of referral letter}

The following information should be contained in the referral letter:

1. Age of the patient

2. Presence or absence of each of the alarm symptoms

3. Any associated signs or symptoms

4. Investigations carried out and results, if known

5. Other medical conditions or treatments (drug, etc)

6. Family history

7. Information given to the patient or patient's carer

8. Day and evening telephone contact for the patient

\section{Quick reference guide}

It is recommended that these symptoms and sign combinations WHEN OCCURRING FOR THE FIRST TIME should be used to identify patients for urgent referral under the two week rule

Symptoms and sign combinations and age threshold

- Rectal bleeding* WITHOUT anal symptoms**: over 50 years

- Change of bowel habit to looser stools and/or increased frequency of defecation persistent for 6 weeks:

With rectal bleeding: all ages

Without rectal bleeding: over 50 years

- Iron deficiency anaemia with positive faecal occult blood WITHOUT an obvious cause (haemoglobin $<100 \mathrm{~g} / \mathrm{ll}$ : over 50 years

- A definite palpable right sided abdominal mass: all ages

- A definite palpable rectal (not pelvic) mass: all ages

* Rectal bleeding according to suggested degree of urgency.

${ }^{*}$ *Anal symptoms include soreness, discomfort, itching, lumps and prolapse as well as pain.

NB. Patients with the following symptoms and no abdominal or rectal mass are at VERY LOW RISK of colorectal cancer:

(1) rectal bleeding with anal symptoms**, (2) change in bowel habit to decreased frequency of defecation and harder stools,

(3) abdominal pain without clear evidence of intestinal obstruction.

practices were involved in the process. All patients but nine $(96.2 \%)$ received appointments within two weeks.

Two patients were excluded from the study. The first patient had undergone barium enema before the referral, which showed colonic carcinoma. The second patient died of unrelated causes shortly after the referral. One patient had carcinoma of the prostate; three patients were found to have distant (hepatic/ pulmonary) metastases or disseminated abdominal malignancy with an unknown primary. They were not classified as colorectal cancers and were grouped as "other" cancers. A total of 231 referrals $(97.5 \%)$ were incomplete. The rest of the findings $(\mathrm{n}=237)$ are summarised in table 1 .

The results (table 1) showed that colorectal cancer diagnosis was of higher frequency in the subgroup of referrals that had complied with the guidelines $(n=18 ; 85.7 \%$ of a total of 21$)$, compared with those that did not $(n=3 ; 14.3 \%$ of a total of 21$)$.

Table 1 Results of compliance with the guidelines and detection of cancer

\begin{tabular}{llll}
\hline & $\begin{array}{l}\text { Guidelines followed } \\
(\mathrm{n}=147)\end{array}$ & $\begin{array}{l}\text { Guidelines not followed } \\
(\mathrm{n}=90)\end{array}$ & $\begin{array}{l}\text { Total } \\
(\mathrm{n}=237)\end{array}$ \\
\hline $\begin{array}{l}\text { Site and Dukes's stage of cancer } \\
\text { Caecum }\end{array}$ & $\mathrm{B}(3)$ & $\mathrm{B}(1), \mathrm{C}(1)$ & 5 \\
$\begin{array}{l}\text { Right colon } \\
\text { Sigmoid colon }\end{array}$ & $\mathrm{D}(1)$ & - & 1 \\
Rectum & $\mathrm{A}(1), \mathrm{B}(1), \mathrm{C}(3)$ & $\mathrm{C}(1)$ & 6 \\
Cancer (all sites) & $\mathrm{A}(3), \mathrm{B}(2), \mathrm{C}(4)$ & - & 9 \\
\hline
\end{tabular}

Table 2 Results of other audits on two week rule

\begin{tabular}{|c|c|c|c|c|c|}
\hline & $\begin{array}{l}\text { Baig et a } \text { l }^{5} \\
\text { (June-Dec 1999) }\end{array}$ & $\begin{array}{l}\text { Baig et a }\left.\right|^{5} \\
\text { (Apr-Nov 2000) }\end{array}$ & Spencer et al & $\begin{array}{l}\text { Riesewyk et a }{ }^{\beta} \\
\text { (Apr-June 2000) }\end{array}$ & $\begin{array}{l}\text { Hemingway } \\
\text { (Aug-Dec 2000) }\end{array}$ \\
\hline Period (months) & 7 & 8 & 3 & 3 & 5 \\
\hline Total referrals & 22 & 67 & 128 & 20 & 37 \\
\hline Non-compliance to the guidelines & $\mathrm{Nil}(0 \%)$ & Low $(8.9 \%)$ & $\operatorname{Low}(-)$ & High (30\%) & Moderate (18.9\%) \\
\hline Total cancer & $2(9 \%)$ & $2(3 \%)$ & $12(9.3 \%)$ & $4(20 \%)$ & $7(18.9 \%)$ \\
\hline Impact on early cancer diagnosis & $\mathrm{Nil}$ & $\mathrm{Nil}$ & Low $(6.2 \%)$ & - & - \\
\hline
\end{tabular}




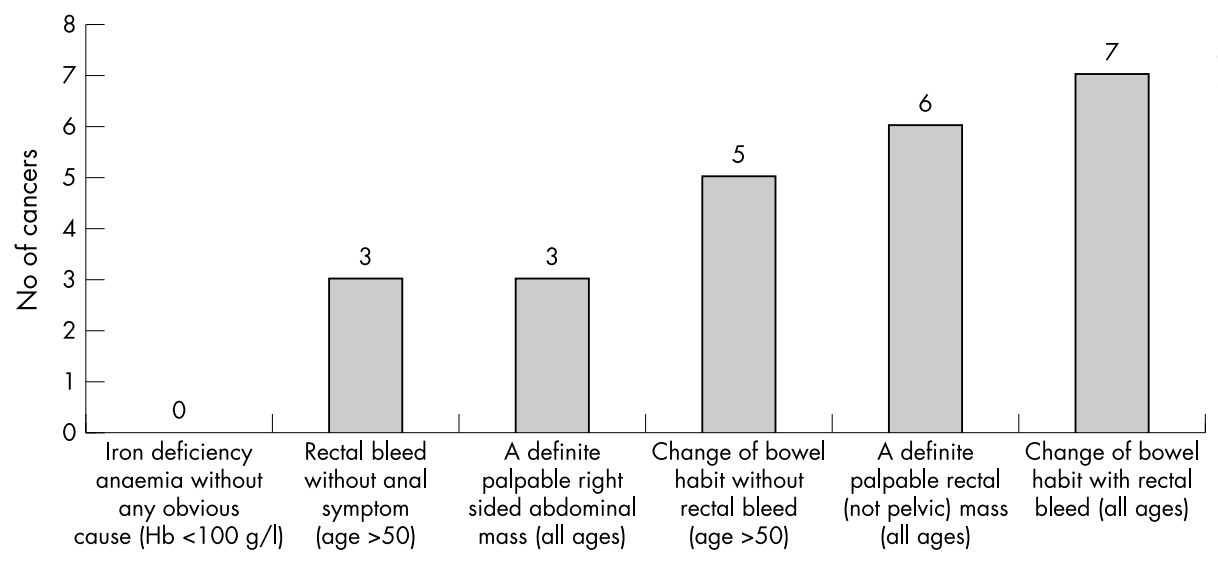

Figure 1 Correlation between criteria for referral and the occurrence of cancer.

The association between cancer diagnosis and compliance with guidelines was statistically significant $\left(\chi^{2}=5.5 ; p=0.019\right)$.

Figure 1 shows the correlation between different criteria for referral and the cancer detection rate. Out of the 18 cancer patients who met the guidelines, 12 were referred with one criterion each. The remaining six patients qualified for two criteria each due to wider symptoms. "Change of bowel habit with rectal bleed" was most commonly (28\%) associated with the occurrence of colorectal cancer. Rectal bleed (32\%) was the most frequent cause for referral among all the patients. Abdominal pain was the commonest (27\%) associated symptom, closely followed by weight loss (16\%). Colonic diverticular disease was the commonest diagnosis (29\%).

Sixty GPs made a total of 90 referrals that failed to comply with the guidelines. Forty seven GPs made one such referral each $(n=47)$. The rest of the referrals $(n=43)$ were forwarded by 17 GPs, several of whom made up to five such referrals.

\section{DISCUSSION}

The rate of cancer detection was $8.9 \%$ over a period of 12 months. The "early" cancer (Dukes's stage A and B) detection rate was $4.6 \%$. Other authors had similar experiences of low "early" cancer detection rates. ${ }^{56}$

A total of $96.2 \%$ of patients received appointments within two weeks. By comparison, average figures in England were 81.2 and $81.8 \%$ during the first and second halves of 2001 respectively. ${ }^{7}$ It reflects the endeavour the trust has made to implement the two week appointment rule.

Table 2 shows comparative figures from similar studies. Spencer et al concluded that the two week wait could be made to run efficiently with high levels of appropriate GP referrals. ${ }^{6}$ Hemingway had commented that urgent review of guidelines was necessary as the latter lacked sufficient sensitivity. ${ }^{9}$

The number of referrals was less than the estimated figure of 2137 per annum (based on a projected number of 1900 referrals per annum per district general hospital serving a population of 200000$).{ }^{4}$ It is possible that it is "early days" and it will take some time to adopt and implement the referral process fully. ${ }^{5}$ Interestingly, this audit did not show any rise in the number of referrals with time.

The audit showed that there was a statistically significant association between cancer diagnosis and compliance with the guidelines. This would suggest that adherence to the guidelines might possibly lead to an improved cancer detection rate.

Another area of interest was the lack of completeness $(97.5 \%)$ of referrals. Family history of cancer and information given to the patient were the two key items that were missed most frequently $(87.3 \%)$. It is worth mentioning that family history is thought to have an influence in $20 \%$ of cases. ${ }^{1}$ It is also helpful to know whether the patient has been made aware of the possibility of cancer. This creates a basis for initiating further discussions, helps focus on specific issues, and improves the quality of communication. A complete referral letter also helps avoid unnecessary duplication of tests.

A total of 96 colorectal cancers were diagnosed (irrespective of the mode of referral) during the same period. Therefore it is apparent that only a small proportion of cancers $(n=21 ; 21.8 \%$ of 96) were diagnosed through the rapid access clinic. However it is important to put the figures in perspective. Approximately $30 \%$ of patients with colorectal cancer are admitted as emergency with obstruction, pain, or perforation. ${ }^{3}$ Hence diagnosis through a rapid access clinic would, at the best, be around $70 \%$ of the total (that is, 67.2 cases out of 96). Taking this factor into account, the cancer detection rate would be $31.2 \%(n=21 ; 31.2 \%$ of 67.2$)$.

\section{Changes}

The audit shows that a high number of referrals are incomplete and non-compliant to the guidelines. The trust has provided two week appointments in most cases, but the cancer diagnosis remains low. This does not reflect an efficient system of referral. Some changes are therefore necessary in order to make the system beneficial to the patients.

We summarise the changes as suggested in the literature:

(1) The key to local implementation is full discussion of shared guidelines followed by continued education in close liaison with primary care providers. ${ }^{10}$ A number of trusts are already involving GPs in collaborative study sessions. ${ }^{3}$ This audit showed that a small number of GPs were responsible for making frequent non-compliant referrals. It would be worth considering whether a focused approach, by targeting training of these GPs, would be more productive.

(2) The two week rule had been seen by the sceptics, ${ }^{11}$ perhaps with reason, as "window dressing" but this also provides an opportunity for further research ${ }^{12}$ and assessment. Therefore a change in attitude is necessary in order to adhere to the guidelines.

(3) It may not be easy to remember the essential features of all the guidelines in a busy practice (there are 11 other such cancer groups!). ${ }^{4}$ It would be worth considering whether a change in the format ${ }^{13}$ of referral letters would help to improve the situation.

A. A mandatory tick box approach (containing all the criteria for referral) that has a direct electronic link with secondary care may be a practical solution. This format is available on NHSWeb but seems to be optional at present. ${ }^{4}$ This would mean that no patient whose condition would fail to meet the guidelines would slip through.

B. There had been a steady increase in the workload of GPs. ${ }^{14}$ An alternative system of referral should therefore be given due consideration. Selvachandran et al has suggested that a new approach is to ask patients to complete their own histories and on history alone, the risk of colorectal cancer can be predicted by using a computerised database questionnaire. ${ }^{15}{ }^{16} \mathrm{~A}$ weighted numerical score based on symptom complexes is calculated, which is comparable to a senior 


\section{Box 2: Learning points}

- The introduction of two week rule had raised controversies.

- The audit showed that there was a statistically significant association between cancer diagnosis and compliance with guidelines.

- A high number of referrals failed to adhere to the guidelines.

- The cancer (particularly "early" cancer) detection rate was low.

- The following changes have been suggested:

(1) Share information on guidelines at local level.

(2) A change in attitude is necessary in order to adhere to the guidelines.

(3) A user-friendly version of referral process may be beneficial.

(4) Consider alternatives to present methods of assessment before referral.

- Further audits are necessary.

- Department of Health believes that some improvements have begun.

surgeon's assessment of the patient consultation questionnaire. This has a high sensitivity and specificity, with a high predictive value. It is said not to add to a GP's workload and makes the achievement of the two week rule possible.

Implementation strategies may be effective methods of achieving compliance. ${ }^{13}$ Audit with feedback is one such recognised strategy and may improve compliance. However, the NHS Centre for Reviews and Dissemination concluded that most strategies could be effective under some circumstances, but none would be effective under all circumstances..$^{17}$

\section{CONCLUSIONS}

The introduction of guidelines entailed good intentions but raised controversies. The current system of referral to the rapid access colorectal clinic is unsatisfactory and it remains speculative whether it will provide any overall benefit to the patients. However, the criteria must be firmly adhered to in order to make correct use of the two week rule. ${ }^{5}$ A concerted effort, including further audits over a considerable period of time, would be necessary to assess the situation. The Depart- ment of Health is presently reviewing progress and believes that some improvements have begun. ${ }^{18}$

\section{ACKNOWLEDGEMENT}

We are very grateful to the audit department, Bishop Auckland General Hospital, for their help in accessing patients' case notes.

\section{Authors' affiliations}

D Debnath, Department of Surgery, University of Aberdeen

N Dielehner, KA Gunning, Department of Surgery, Darlington Memorial Hospital, South Durham Health Care Trust, Darlington

\section{REFERENCES}

1 Colorectal Site Specific Group. Cancer Care Alliance of Teeside, South Durham and North Yorkshire. Colorectal cancer guidelines. Available from James Cook University Hospital, Middlesbrough TS4 3BW, UK.

2 Baig MK, Marks CG. Referral guidelines for colorectal cancer: a threat or a challenge? Hosp Med 2000;61:452-3.

3 James R. Rapid access colorectal clinics and two week wait. Colonews 2000;9(1):7.

4 NHS Executive, Department of Health. Referral guidelines for suspected cancer. 31 March 2000 (http://www.doh.gov.uk/pub/docs/doh/ guidelines.pdf).

5 Baig MK, Marks CG, Stebbing JF, et al. 2-week rule [rapid response] BM Online 16 January 2001 (http://bmj.com)

6 Spencer $\mathrm{H}$, Heeley $\mathrm{R}$, Murray I, et al. 2 week cancer wait list [rapid response]. BM Online 18 January 2001 (http://bmj.com).

7 Department of Health. Cancer waiting times-monitoring the "two Department of Health. Cancer waiting times-monitoring the "two
week target" 7 December 2001 (http://www.doh.gov.uk/cancerwaits) 8 Riesewyk C, Hayward C, Enser V, et al. Referral and diagnostic process in suspected colorectal cancer needs to be improved to achieve two week target. BM 2000:321:1527.

9 Hemingway D. Two week target for cancer referral [rapid response]. BM Online 15 January 2001 (http://bmi.com).

10 Davies E, Van der Molen B. The initiative should not be dismissed. BM 2000;320: 1476 .

11 Sikora K. New guidelines for urgent referral of patients with cancer are waste of energy. BM 2000;320:59.

12 Summerton N. Patients will have a dignified end to life. BM 2000;320:1476.

13 Baker R. Is it time to review the idea of compliance with guidelines? $\mathrm{Br} J$ Gen Pract 2001;51:7

14 Olsen ND. Sustaining general practice. BM 1996;312:525-6.

15 Selvachandran S, Ballal M, Hodder R, et al. Inprocess citation of a different approach to improve the referral and diagnostic process [rapid response]. BM Online 16 January 2001 (http://bmi.com).

16 Hodder R, Ballal M, Selvachandran S, et al. Colorectal referral assessment protocols. Ann R Coll Surg Engl 2002;84:282.

17 NHS Centre for Reviews and Dissemination (University of York). Getting evidence into practice. Effective Health Care 1999;5(1):1-16.

18 Department of Health. Cancer waiting times: guidance on making and tracking progress on cancer waiting times. Health service circular number 2002/005. 18 March 2002 (http://www.doh.gov.uk/publications/ coinh.html). 